J Nat Prod. 2016 April 22; 79(4): 1219-1222. doi:10.1021/acs.jnatprod.6b00057.

\title{
The Natural Product Essramycin and Three of Its Isomers Are Devoid of Antibacterial Activity
}

\author{
Huan Wang, Dusan Hesek, Mijoon Lee, Elena Lastochkin, Allen G. Oliver, Mayland Chang*, \\ and Shahriar Mobashery ${ }^{*}$ \\ Department of Chemistry and Biochemistry, University of Notre Dame, 423 Nieuwland Hall, Notre \\ Dame, Indiana 46556, United States
}

\section{Abstract \\ Four possible isomers of essramycin, a natural product from a marine Streptomyces species isolated from the Egyptian Mediterranean coast, were synthesized. The structures for the isomers were assigned unequivocally by ${ }^{1} \mathrm{H}$ NMR, ${ }^{13} \mathrm{C}$ NMR, high-resolution mass spectrometry, and $\mathrm{X}$ - ray crystal structure determinations. Notwithstanding the earlier report of broad-spectrum antibacterial activity for the natural product, none of the four isomers exhibited any such activity.}

\section{Graphical Abstract}

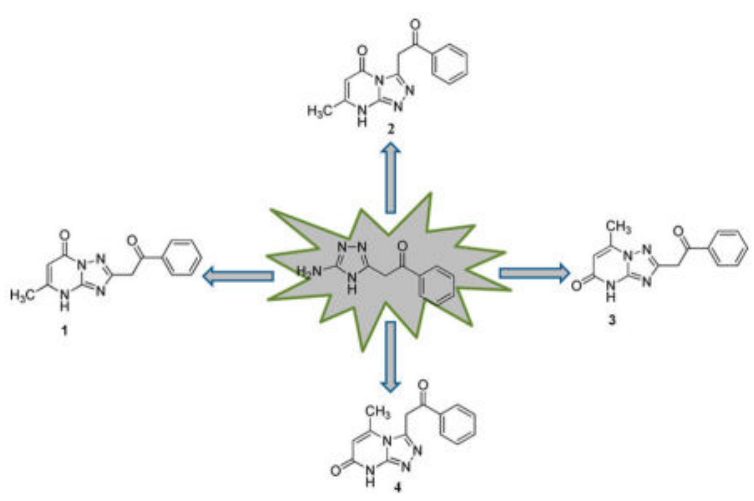

We recently described the discovery of a family of triazolopyrimidines, which showed narrow-spectrum antibacterial activity against the human pathogen Enterococcus faecium. ${ }^{1}$ The hit target for this discovery had emerged from in silico docking and scoring exercises. The structure of the hit molecule was further elaborated by synthesis of a library of 68 triazolopyrimidines, which were then screened for antibacterial activity. In the course of this

"Corresponding Authors: mchang@nd.edu. mobashery@nd.edu.

The authors declare no competing financial interest.

Supporting Information

The Supporting Information is available free of charge on the ACS Publications website at DOI: 10.1021/acs.jnat-prod. $6 \mathrm{~b} 00057$.

Supplementary tables and figures; ${ }^{1} \mathrm{H}$ and ${ }^{13} \mathrm{C}$ NMR spectra for compounds $\mathbf{1}, \mathbf{2}, \mathbf{3}$, and $\mathbf{4}$ (PDF)

Crystallographic data for 1-4 (CIF) 
effort, we were delighted to identify a work from 2008 that indeed reported the isolation and characterization of a natural product triazolopyrimidine, essramycin, which was reported to exhibit broad-spectrum (both Gram-positive and Gram-negative) antibacterial activity, although few strains of bacteria were tested. ${ }^{2}$ Essramycin was purified from a Streptomyces sp. (Merv8102) isolated from the Egyptian Mediterranean coast. Its structure was determined to be that of compound 1 (Figure 1) by spectrophotometric methods.

Intrigued by the reported broad-spectrum activity for essramycin, which contrasted with the narrow-spectrum activities of our own triazolopyrimidines, we synthesized essramycin (described below). Unfortunately, we could not document any antibacterial activity for the synthetic essramycin. We note that two other laboratories synthesized 1 independently, and Cooper's group reported the lack of antibacterial activity as well. ${ }^{3,4}$ This led us to inquire whether the natural product could possibly be one of the three other isomers, compound $\mathbf{2}, \mathbf{3}$, or 4 (Figure 1). These isomers might be difficult to differentiate based on some of the spectroscopic methods that were employed in the original report. The additional three isomers were synthesized, and they were tested against the ESKAPE panel of bacterial

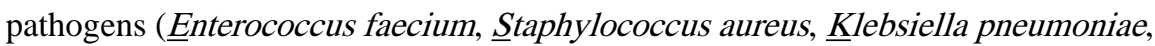
Acinetobacter baumannii, $\underline{P}$ seudomonas aeruginosa, and Enterobacter species; the underlined first letters for the names of genera form the acronym). The ESKAPE panel includes both Gram-positive and Gram-negative bacteria and accounts for the majority of nosocomial human pathogens. To our dismay, none of the four isomers exhibited any antibacterial activity against the ESKAPE panel in our hands.

Three synthetic routes were used to prepare all four compounds (Figure 2A). All three reactions utilize 2-(5-amino-4H-1,2,4-triazol-3-yl)-1-phenylethanone (5) as the precursor, whereas each uses different esters (6-8) to construct the pyrimidinone ring. Isomer $\mathbf{1}$ was prepared by reaction A, which used triazole 5 and ethyl acetoacetate (6) in acetic acid. This was the reaction used in syntheses of essramycin by the Cooper and Moody laboratories. ${ }^{3,4}$ Reaction B produced compound $\mathbf{2}$ (minor product) and compound $\mathbf{3}$ (major product), which were separated chromatographically. This reaction allowed reagent 5 to react with ethyl 3ethoxy-2-butenoate (7) in the presence of sodium in methanol, under reflux for $24 \mathrm{~h}$. Compound 4 was prepared by reaction $\mathrm{C}$, which was obtained by reflux of 5 and methyl 2butynoate (8) in $n$-butanol.

Side-by-side comparisons of all four isomers were made. All four compounds gave highresolution mass spectra corresponding to the empirical formula $\mathrm{C}_{14} \mathrm{H}_{12} \mathrm{~N}_{4} \mathrm{O}_{2}$. Thin-layer chromatographs on silica gel plates were distinct (eluted with 20:1 dichloromethanemethanol), with $R_{f}$ values of $0.29,0.32,0.26$, and 0.23 for compounds $\mathbf{1}, \mathbf{2}, \mathbf{3}$, and $\mathbf{4}$, respectively. Also their HPLC retention times $\left(t_{\mathrm{R}}\right)$ were different at 3.1, 3.0, 3.3, and 3.2 min, respectively, under the same conditions $\left(\mathrm{C}_{8}\right.$ column with isocratic elution in wateracetonitrile (70:30) containing 0.1\% TFA; see Experimental Section for details; Figure 2B). Furthermore, the chemical structures for isomers $\mathbf{1}, \mathbf{3}$, and $\mathbf{4}$ were unequivocally established by determination of the X-ray crystal structures (Figure 2A and Supporting Information). ${ }^{5} \mathrm{H}$ and ${ }^{13} \mathrm{C}$ NMR spectra of compounds $1,2,3$, and 4 were obtained and compared to each other and to those in the literature for $\mathbf{1}$ (Table 1 and Supporting Information). 
Subsequently, we evaluated the antibacterial activity of all four isomers against the ESKAPE panel of bacterial pathogens, as indicated earlier. We could not document any antibacterial activity for any of the four isomers. The purpose for this Note is to set the record ${ }^{4}$ straight on the lack of antibacterial activity for essramycin, so others would not dedicate effort and resources on this natural product. Indeed, Streptomyces have been a major source of antibiotics of many different classes. ${ }^{6-8}$ We assume that the sample of essramycin isolated from Streptomyces might have been contaminated by a potent broad-spectrum antibiotic, which would have led to the observation of antibacterial activity that was attributed to essramycin. The presumed potency is based on the consideration that the activity that was documented was respectable and, since it should have come from the minor component, it would impart significant potency to the contaminating antibiotic. It would be worthwhile to return to the original Streptomyces species to investigate the chemical nature of the contaminating antibiotic that copurified with essramycin.

\section{EXPERIMENTAL SECTION}

\section{General Experimental Procedures}

All chemicals, reagents, and solvents were used directly as purchased without purification. All synthesized compounds were characterized by ${ }^{1} \mathrm{H}$ NMR and ${ }^{13} \mathrm{C}$ NMR spectroscopy using DMSO- $d_{6}$ as solvent. NMR spectra are reported in chemical shifts in parts per million (ppm) relative to the residual solvents: DMSO- $d_{6} 2.50$ and $39.5 \mathrm{ppm}$ for ${ }^{1} \mathrm{H}$ and ${ }^{13} \mathrm{C}$ NMR. ${ }^{1} \mathrm{H}$ and ${ }^{13} \mathrm{C}$ NMR spectra were recorded on Bruker AVANCE III HD 400 spectrometers (Bruker Daltonik, Bremen, Germany) equipped with BBFO probes and operating at ${ }^{1} \mathrm{H}$ resonance frequencies of $400.13 \mathrm{MHz}$. High-resolution mass spectra were measured using a Bruker micrOTOF/Q2 mass spectrometer in ESI ionization. An arbitrary hemisphere of X-ray diffraction data for each of compounds $\mathbf{1}, \mathbf{3}$, and $\mathbf{4}$ was recorded on a dual-source 3-circle Bruker APEX-II diffractometer using either Mo $\mathrm{Ka}$ or $\mathrm{Cu} \mathrm{Ka}$ radiation at $120 \mathrm{~K}$. Data were corrected for absorption effects and solved and refined routinely. The reaction was monitored by using thin-layer chromatography on silica gel $60-\mathrm{F}_{254}$ plates. The product was purified by using CombiFlash Rf 200i purification system.

2-(5-Amino-4H-1,2,4-triazol-3-yl)-1-phenylethanone (5)-It was prepared according to a literature method. ${ }^{3}$

5-Methyl-2-(2-oxo-2-phenylethyl)-[1,2,4]triazolo[1,5-a]-pyrimidin-7(1H)-one (1) -Compound 1 was prepared by use of a literature method (Figure $2 \mathrm{~A}$, reaction A). ${ }^{3}$ The title compound was purified by chromatography on silica gel $\left(1: 9, \mathrm{MeOH}-\mathrm{CH}_{2} \mathrm{Cl}_{2} ; 0.82 \mathrm{~g}\right.$, $90 \%$ ). Crystals were grown by dissolving the compound in $\mathrm{CH}_{2} \mathrm{Cl}_{2}-\mathrm{MeOH}$-acetonitrile (5:0.5:1) and allowing slow solvent evaporation over 5 days. The $\mathrm{X}$-ray crystal structure of compound 1 was obtained. HRMS: calcd for $\mathrm{C}_{14} \mathrm{H}_{13} \mathrm{~N}_{4} \mathrm{O}_{2}(\mathrm{M}+\mathrm{H})^{+} 269.1033$; found 269.1059. The ${ }^{1} \mathrm{H}$ and ${ }^{13} \mathrm{C}$ NMR spectra of compound $\mathbf{1}$ are given in Tables 1 and 2.

7-Methyl-3-(2-oxo-2-phenylethyl)-[1,2,4]triazolo[4,3-a]-pyrimidin-5(1 H)-one (2) and 7-Methyl-2-(2-oxo-2-phenyleth-yl)-[1,2,4]triazolo[1,5-a]pyrimidin-5(1H)-one

(3)-Compound $\mathbf{2}$ and compound $\mathbf{3}$ are new compounds and were prepared via a 
modification of the reported method (Figure 2A, reaction B) for the preparation of triazolopyrimidines. ${ }^{9}$ Sodium $(0.25 \mathrm{~g}, 11 \mathrm{mmol})$ was added to anhydrous methanol $(11 \mathrm{~mL})$, followed by the addition of $5(2.23 \mathrm{~g}, 11 \mathrm{mmol})$. Subsequently ethyl 3-ethoxy-2-butenoate $(7,1.75 \mathrm{~g}, 11 \mathrm{mmol})$ was added, and the mixture was refluxed for $24 \mathrm{~h}$. After evaporation of the solvent in vacuo, the mixture was purified by a CombiFlash Rf 200i purification system (eluting with $\mathrm{MeOH}-\mathrm{CH}_{2} \mathrm{Cl}_{2}, 0 \% \mathrm{MeOH}$ for $5 \mathrm{~min}, 2 \% \mathrm{MeOH}$ for $35 \mathrm{~min}$, a gradient of 2$100 \% \mathrm{MeOH}$ over $20 \mathrm{~min}, 100 \% \mathrm{MeOH}$ for $10 \mathrm{~min}$ ), which produced pure samples of compound 2 (5.9 mg, 0.2\%) and compound 3 (0.89 g, 30\%). Compound 2 was a light yellow solid, and compound 3 was a white solid. The compound was dissolved in $\mathrm{CH}_{2} \mathrm{Cl}_{2}-\mathrm{MeOH}$ (20:1), and the solvent was allowed to slowly evaporate over 3 days, during which crystals formed. The X-ray crystal structure of compound 3 was obtained. HRMS: calcd for $\mathrm{C}_{14} \mathrm{H}_{13} \mathrm{~N}_{4} \mathrm{O}_{2}(\mathrm{M}+\mathrm{H})^{+}$269.1033; found 269.1071 (compound 2). HRMS: calcd for $\mathrm{C}_{14} \mathrm{H}_{13} \mathrm{~N}_{4} \mathrm{O}_{2}(\mathrm{M}+\mathrm{H})^{+}$269.1033; found 269.1021 (compound 3). ${ }^{1} \mathrm{H}$ and ${ }^{13} \mathrm{C} \mathrm{NMR}$ spectra of compounds $\mathbf{2}$ and $\mathbf{3}$ are given in Tables 1 and 2 .

\section{5-Methyl-3-(2-oxo-2-phenylethyl)-[1,2,4]triazolo[4,3-a]-pyrimidin-7(1 H)-one (4)} -Compound 4 is a new compound and was prepared by reaction C of Figure $2 \mathrm{~A} .{ }^{10}$ Reagent 5 (1.09 g, $5.40 \mathrm{mmol})$ in $n$-butanol $(5 \mathrm{~mL})$ was mixed with methyl 2-butynoate $(\mathbf{8}, 0.56 \mathrm{~g}$, $5.73 \mathrm{mmol}$ ), followed by reflux for $24 \mathrm{~h}$. The solvent was removed in vacuo, and the product was purified on a CombiFlash Rf 200i purification system with the same solvent elution described above, to produce compound 3 (73 mg, 5\%) and compound 4 (0.36 g, 25\%).

Compound 4 was a white solid. The solid was dissolved in $\mathrm{CH}_{2} \mathrm{Cl}_{2}-\mathrm{MeOH}$ (30:1), and the solvent was allowed to evaporate slowly over 4 days, during which crystals grew. The X-ray crystal structure of compound 4 was obtained. HRMS: calcd for $\mathrm{C}_{14} \mathrm{H}_{13} \mathrm{~N}_{4} \mathrm{O}_{2}(\mathrm{M}+$ $\mathrm{H})^{+}$269.1033; found 269.1058. ${ }^{1} \mathrm{H}$ and ${ }^{13} \mathrm{C}$ NMR spectra of compound 4 are given in Tables 1 and 2 .

\section{Minimal Inhibitory Concentration (MIC) Determination}

The procedure for MIC determination against the ESKAPE panel of bacteria ( $E$. faecium NCTC 7171 (ATCC 19734), $S$. aureus ATCC 29213, K. pneumonia ATCC 700603, $A$. baumanii ATCC 17961, P. aeruginosa ATCC 27853, E. aerogenes ATCC 35029, E. coli ATCC 25922) was as described previously. ${ }^{11}$ All four isomers were evaluated for antibacterial activity in a range of concentrations, with the high concentration of $128 \mu \mathrm{g} / \mathrm{mL}$. Meropenem and vancomycin were used as the positive controls. No antibacterial activity was noted.

\section{High-Performance Liquid Chromatography (HPLC)}

The HPLC instrument consisted of a PerkinElmer series 200 autosampler, series 200 UV/vis detector, and series 200 pump, using TotalChrom Navigator software (PerkinElmer, Shelton, CT, USA). The HPLC conditions consisted of isocratic elution on a Zorbax $\mathrm{Rx}-\mathrm{C}_{8} 5 \mu \mathrm{m}, 4.6$ $\times 250 \mathrm{~mm}$ column (Agilent Technologies, Santa Clara, CA, USA) at a flow rate of $1 \mathrm{~mL} / \mathrm{min}$ with $70 \% \mathrm{~A} / 30 \% \mathrm{~B}$ for $15 \mathrm{~min}(\mathrm{~A}=0.1 \%$ trifluoroacetic acid-water; $\mathrm{B}=0.1 \%$

trifluoroacetic acid-acetonitrile). Effluent was detected at $254 \mathrm{~nm}$. All synthetic compounds were $\geq 96 \%$ pure. 


\section{X-ray Parameters for Compounds 1, 3, and 4}

Complete crystal and structure refinement data are given in the Supporting Information (Table S1).

Crystal data for $1-\mathrm{C}_{14} \mathrm{H}_{12} \mathrm{~N}_{4} \mathrm{O}_{2} ; M_{\mathrm{r}}=268.28$; orthorhombic; space group Pca2 $;$; $a=$ 29.815(16) $\AA ; \quad b=4.718(2) \AA ; c=8.617(5) \AA ; a=90^{\circ} ; \beta=90^{\circ} ; \gamma=90^{\circ} ; V=1212.2(11)$ $\AA^{3} ; Z=4 ; T=120(2) \mathrm{K} ; \lambda($ Mo Ka $)=0.71073 \AA$ А $\mu($ Mo Ka $)=0.103 \mathrm{~mm}^{-1} ; d_{\text {calc }}=1.470$ $\mathrm{g} \cdot \mathrm{cm}^{-3} ; 4262$ reflections collected; 1629 unique $\left(R_{\mathrm{int}}=0.0600\right)$, giving $R_{1}=0.0569, w R_{2}=$ 0.1250 for 1201 data with $[I>2 \sigma(I)]$ and $R_{1}=0.0823, w R_{2}=0.1327$ for all 1629 data. Residual electron density $\left(\mathrm{e}^{-} \cdot \AA^{-3}\right) \mathrm{max} / \mathrm{min}: 0.257 /-0.278$.

Crystal data for $3-\mathrm{C}_{14} \mathrm{H}_{12} \mathrm{~N}_{4} \mathrm{O}_{2} ; M_{\mathrm{r}}=268.28$; monoclinic; space group $P 2 / n$; $a=$ 5.5805(2) $\AA ; \quad b=8.5947(4) \AA ; c=25.8960(11) \AA ; a=90^{\circ} ; \beta=93.211(2)^{\circ} ; \gamma=90^{\circ} ; V=$ 1240.09(9) $\AA^{3} ; Z=4 ; T=120(2) \mathrm{K} ; \lambda ;(\mathrm{Cu} \mathrm{Ka})=1.54184 \AA$; $\mu(\mathrm{Cu} \mathrm{Ka})=0.828 \mathrm{~mm}^{-1}$; $d_{\text {calc }}=1.437 \mathrm{~g} \cdot \mathrm{cm}^{-3} ; 22121$ reflections collected; 2421 unique $\left(R_{\mathrm{int}}=0.0428\right)$, giving $R_{1}=$ $0.0432, w R_{2}=0.1145$ for 2265 data with $[I>2 \sigma(I)]$ and $R_{1}=0.0453, w R_{2}=0.1158$ for all 2421 data. Residual electron density $\left(\mathrm{e}^{-} \cdot \AA^{-3}\right) \max / \min : 0.265 /-0.261$.

Crystal data for 4- $\mathrm{C}_{14} \mathrm{H}_{12} \mathrm{~N}_{4} \mathrm{O}_{2} ; M_{\mathrm{r}}=268.28$; monoclinic; space group $P 2_{1} / c ; a=$ $11.0776(12) \AA ; \quad b=15.1099(16) \AA ; c=7.6255(8) \AA ; a=90^{\circ} ; \beta=108.0000(10)^{\circ} ; \gamma=90^{\circ}$; $V=1213.9(2) \AA^{3} ; Z=4 ; T=120(2) \mathrm{K} ; \lambda(\mathrm{Mo} \mathrm{K} a)=0.71073 \AA ; \mu(\mathrm{Mo} \mathrm{K} a)=0.103 \mathrm{~mm}^{-1}$; $d_{\text {calc }}=1.468 \mathrm{~g} \cdot \mathrm{cm}^{-3} ; 25058$ reflections collected; 3567 unique $\left(R_{\text {int }}=0.0214\right)$, giving $R_{1}=$ $0.0360, w R_{2}=0.0975$ for 3292 data with $[I>2 \sigma(I)]$ and $R_{1}=0.0385, w R_{2}=0.1001$ for all 3567 data. Residual electron density $\left(\mathrm{e}^{-} \cdot \AA^{-3}\right) \mathrm{max} / \mathrm{min}: 0.434 /-0.206$.

\section{Supplementary Material}

Refer to Web version on PubMed Central for supplementary material.

\section{Acknowledgments}

This work was supported by grant AI90818 from the NIH. H.W. was supported by a Predoctoral Fellowship from the Eck Institute for Global Health, University of Notre Dame.

\section{References}

1. Wang H, Lee M, Peng Z, Blázquez B, Lastochkin E, Kumarasiri M, Bouley R, Chang M, Mobashery S. J Med Chem. 2015; 58:4194-4203. [PubMed: 25923368]

2. El-Gendy MM, Shaaban M, Shaaban KA, El-Bondkly AM, Laatsch H. J Antibiot. 2008; 61:149_ 157. [PubMed: 18503193]

3. Battaglia U, Moody CJ. J Nat Prod. 2010; 73:1938-1939. [PubMed: 20836523]

4. Tee EH, Karoli T, Ramu S, Huang JX, Butler MS, Copper MA. J Nat Prod. 2010; 73:1940-1942. [PubMed: 21049974]

5. Crystallographic data for the structure(s) reported in this paper have been deposited with the Cambridge Crystallographic Data Centre (CCDC 1449053-1449055). Copies of the data can be obtained, free of charge, on application to the Director, CCDC, 12 Union Road, Cambridge CB2 1EZ, UK (fax: + 44-(0)1223-336033 or e-mail: deposit@ ccdc.cam.ac.uk).

6. Antoraz S, Santamaría RI, Díaz M, Sanz D, Rodríguez H. Front Microbiol. 2015; 6:1-8. [PubMed: 25653648] 
7. Watve MG, Tickoo R, Jog MM, Bhole BD. Arch Microbiol. 2001; 176:386-390. [PubMed: 11702082]

8. Liu G, Chater KF, Chandra G, Niu G, Tan H. Microbiol Mol Biol Rev. 2013; 77:112-143. [PubMed: 23471619]

9. Williams L. J Chem Soc. 1961; 0:3046-3052.

10. Reimlinger H, Jacquier R, Daunis. Chem Ber. 1971; 104:2702-2708.

11. O'Daniel PI, Peng ZH, Pi H, Testero SA, Ding D, Spink E, Leemans E, Boudreau MA, Yamaguchi T, Schroeder VA, Wolter WR, Llarrull LI, Song W, Lastochkin E, Kumarasiri M, Antunes NT, Espahbodi M, Lichtenwalter K, Suckow MA, Vakulenko S, Mobashery S, Chang M. J Am Chem Soc. 2014; 136:3664-3672. [PubMed: 24517363] 
<smiles>Cc1cc(=O)n2nc(CC(=O)c3ccccc3)nc2[nH]1</smiles>

Figure 1.

Four possible isomers (1-4) for the natural product essramycin. The structure of compound 1 was attributed to essramycin by ${ }^{1} \mathrm{H}$ NMR, ${ }^{13} \mathrm{C}$ NMR, HMBC, HRMS, and IR experiments. $^{2}$ 
A

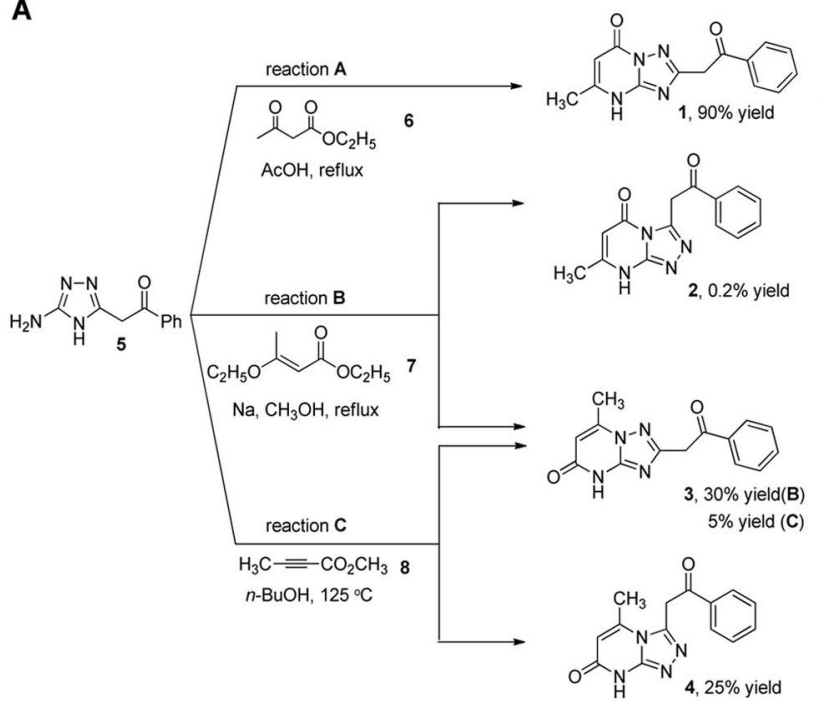

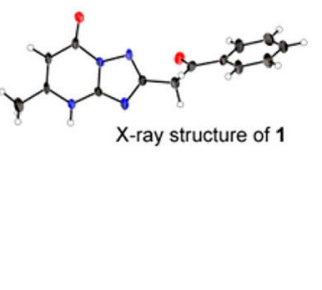
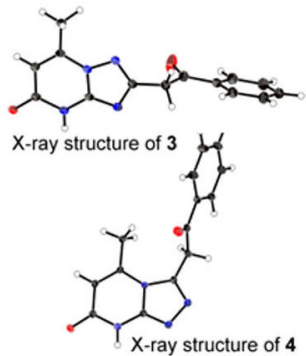

B
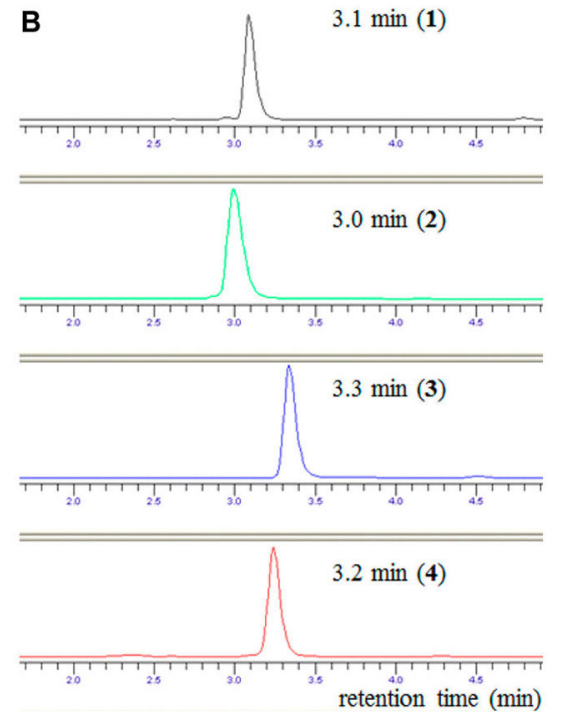

Figure 2.

(A) Synthetic routes to triazolopyrimidine isomers $1,2,3$, and 4 . Compounds 1,3 , and 4 crystallized, and their structures were determined by X-ray crystallography. (B) HPLC chromatograms of the individual isomers. 


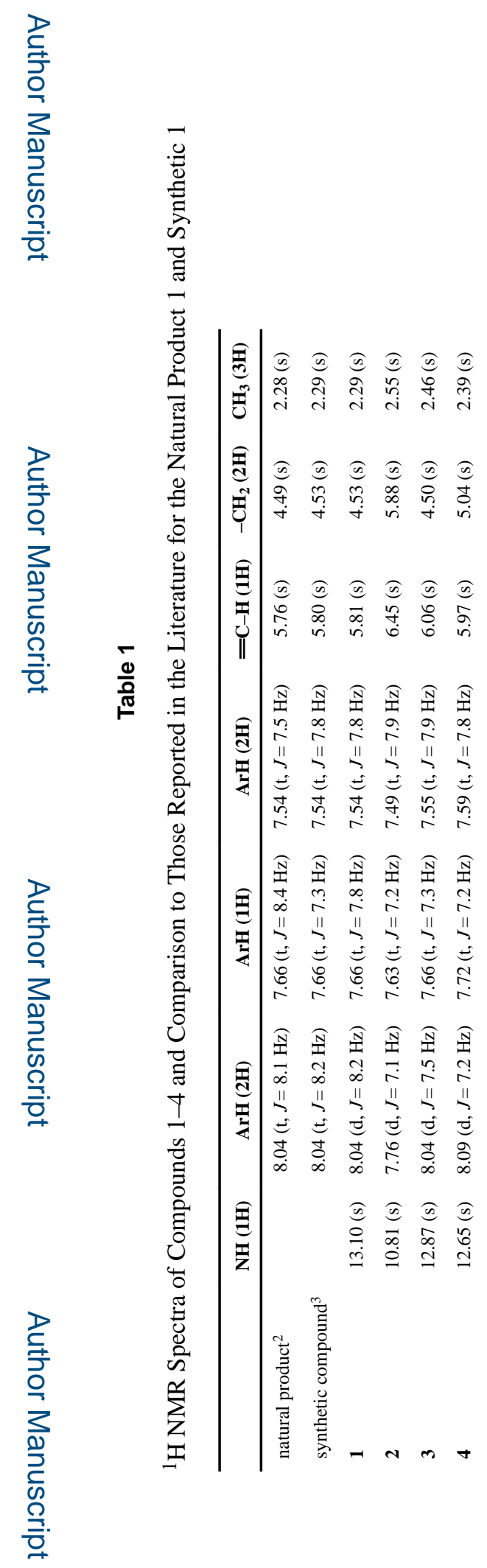

J Nat Prod. Author manuscript; available in PMC 2017 May 18. 


\section{Table 2}

${ }^{13}$ C NMR Spectra of Compounds 1-4 and Comparison to Those Reported in the Literature for the Natural Product 1 and Synthetic 1

\begin{tabular}{lllrc}
\hline & $\mathbf{C = O}$ & ArC & $=\mathbf{C}-\mathbf{H}$ & aliphatic C \\
\hline natural product $^{2}$ & 195.0 & $159.0,155.6,151.9,151.4,136.0,133.4,128.6,128.4$ & 97.9 & $38.0,18.9$ \\
synthetic compound $^{3}$ & 195.1 & $159.2,155.5,150.9,136.0,133.6,128.8,128.5$ & 98.3 & $39.5,18.6$ \\
$\mathbf{1}$ & 195.0 & $159.2,155.5,150.8,136.0,133.5,128.7,128.5,125.2$ & 98.2 & $39.1,18.5$ \\
$\mathbf{2}$ & 192.3 & $156.3,149.8,139.9,139.3,137.2,133.3,129.1,128.5$ & 102.4 & $40.1,17.3$ \\
$\mathbf{3}$ & 195.0 & $159.3,150.1,147.2,136.0,133.5,128.7,128.4,125.1$ & 105.2 & $38.9,16.1$ \\
$\mathbf{4}$ & 196.2 & $149.6,144.8,142.1,135.4,134.1,128.9,128.6,125.3$ & 108.3 & $38.3,17.3$
\end{tabular}

